\title{
A New Clinical Model for Prediction of Nodal Metastasis for Patients with Early Gastric Cancer: Is this Good Enough?
}

\author{
June Lee, MBBS, FRCSEd (Gen) and Philip W.Y. Chiu, MD, FRCSEd (Gen) \\ Department of Surgery, Institute of Digestive Disease, Prince of Wales Hospital, The Chinese University of Hong Kong, \\ Hong Kong, China
}

Early gastric cancer (EGC), an entity that was first recognized in 1962 by the Japanese Society of Gastroenterological Endoscopy, refers specifically to gastric cancer that is confined to the mucosa $\left(\mathrm{T}_{1} \mathrm{a}\right)$ or submucosa $\left(\mathrm{T}_{1} \mathrm{~b}\right)$ layer irrespective of lymph node involvement. ${ }^{1}$ Such a distinction was established based on the observation that patients with EGC have an excellent prognosis after conventional gastrectomy with standardized lymph node dissection. Although nodal status does not affect the designation of EGC, lymph node metastasis is one of the most important prognostic factor. ${ }^{2}$ As a result, gastrectomy with regional lymphadenectomy remained the gold standard for treatment of EGC. ${ }^{3}$ However, radical gastrectomy with standard D2 nodal dissection is associated with significant risks of morbidity and mortality, and further compromises patients' quality of life. ${ }^{4}$ Endoscopic resection emerged as a highly attractive alternative, because it preserves the stomach and averts all the complications associated with gastrectomy. ${ }^{5}$ Because endoscopic resection provides only local treatment without lymph node dissection, it should only be performed for EGC with absence of nodal metastases.

The overall incidence of lymph node metastases in EGC ranged from 0 to $15 \%$; the rate was $0-3 \%$ for intramucosal carcinomas and 11-20\% for submucosal tumors. ${ }^{6}$ Conventionally, the absolute indication for endoscopic resection of EGC was a well-differentiated, nonulcerative intramucosal carcinoma of less than $2 \mathrm{~cm}$ according to the Japanese guidelines. Gotoda et al. reviewed the nodal

(C) Society of Surgical Oncology 2015

First Received: 2 March 2015;

Published Online: 20 March 2015

P. W.Y.Chiu, MD, FRCSEd (Gen)

e-mail: philipchiu@surgery.cuhk.edu.hk metastasis from gastrectomy specimens for patients with EGCs and identified a subgroup of patients with nonulcerative, intramucosal, well-differentiated EGC who have virtually no risk of nodal metastases. Consequently, the criteria for endoscopic resection was expanded (Table 1) as included in the current Japanese gastric cancer treatment guidelines to allow endoscopic resection of well-differentiated intramucosal EGC of any size. ${ }^{7}$ Although patients with nonulcerative superficial submucosal EGC of less than $3 \mathrm{~cm}$ were considered as adequately treated by endoscopic resection under the expanded criteria, there was still a low but definite risk of nodal metastasis. The clinical issue is how to better predict the risk of nodal metastasis for patients with EGC.

Fujikawa and colleagues attempted to answer this question by coming up with a new prediction model of nodal status in patients with EGC - one that relies solely on clinical parameters, thereby improving its utility and practicality among clinicians. ${ }^{8}$ Of their 511 patients with $\mathrm{T} 1$ gastric cancer who did not meet the absolute criteria for endoscopic resection and thus received radical gastrectomy, 465 were found on pathology to have $\mathrm{N}_{0}$ disease. This suggested that radical gastrectomy was overtreating $91 \%$ of their cohort of patients. Upon multivariate analysis, tumor diameter, depth of invasion, and histological type were significant independent clinical risk factors for nodal metastasis. These parameters were combined to calculate Fujikawa's prediction model (Table 2). This model was able to further identify more than two-thirds of EGC patients without nodal metastasis who do not fall into the absolute criteria for endoscopic resection according to the Japanese guidelines. The ability of Fujikawa's predictive criteria to identify new EGC candidates for endoscopic treatment based solely on clinical factors that can be obtained before treatment is very appealing. However, the caveats to reproducing these results depended heavily on 
TABLE 1 Expanded criteria of early gastric cancer for endoscopic resection

\begin{tabular}{|c|c|c|c|}
\hline $\begin{array}{l}\text { Clinical } \\
\text { depth }\end{array}$ & $\begin{array}{l}\text { Histopathological } \\
\text { type }\end{array}$ & $\begin{array}{l}\text { Macroscopic } \\
\text { type }\end{array}$ & $\begin{array}{l}\text { Maximum tumor } \\
\text { diameter }(\mathrm{mm})\end{array}$ \\
\hline Clinical $\mathrm{T}_{1} \mathrm{a}$ & Differentiated type & Nonulcerated & Unlimited \\
\hline Clinical $\mathrm{T}_{1} \mathrm{a}$ & Differentiated type & Ulcerated & 30 \\
\hline Clinical $\mathrm{T}_{1} \mathrm{a}$ & Undifferentiated type & Nonulcerated & 20 \\
\hline
\end{tabular}

TABLE 2 Fujikawa's predictive model of cutoff values of tumor diameter to predict nodal metastases

\begin{tabular}{lll}
\hline $\begin{array}{l}\text { Clinical } \\
\text { depth }\end{array}$ & $\begin{array}{l}\text { Histopathological } \\
\text { type }\end{array}$ & $\begin{array}{l}\text { Maximal tumor } \\
\text { diameter }(\mathrm{mm})\end{array}$ \\
\hline Clinical $\mathrm{T}_{1} \mathrm{a}$ & $\begin{array}{l}\text { Differentiated type } \\
\text { Undifferentiated type }\end{array}$ & 79 \\
Clinical $\mathrm{T}_{1} \mathrm{~b}$ & Differentiated type & 48 \\
& Undifferentiated type & 11 \\
\hline
\end{tabular}

the accuracy of tumor depth and size measurements, which were determined by endoscopy and imaging studies in this study. Fujikawa's group showed a highly accurate clinical tumor depth assessment of $92.4 \%$. In contrast, a much lower accuracy of predicting tumor depth were reported from other studies on endoscopic features (78\%) and endoscopic ultrasonography $(67-72 \%) .^{9-11}$ This suggests that Fujikawa's predictive criteria may not demonstrate sufficient external validity.

Because of the modest diagnostic accuracy of tumor depth seen in endoscopy and EUS, endoscopic resection of EGC is performed by expert endoscopists as both a staging and treatment procedure. ${ }^{12}$ Meanwhile, advances in endoscopic submucosal dissection (ESD) allow complete en bloc resection and pathological staging of the EGC while not precluding subsequent surgical therapy if the histopathology demonstrated unfavorable findings that suggest a higher likelihood of nodal metastases like poor differentiation and lymphovascular permeation. ${ }^{13}$ For this reason, ESD is considered as a staging procedure for EGC with undetermined risk of nodal metastasis in Japan and some Asian countries.

The negative predictive value from Fujikawa's prediction model was $95.7 \%$, which would be further enhanced to $98.2 \%$ if lymphovascular permeation was found in the specimen after ESD. However, AUC for the ROC curve in this predictive model was only 0.75 . Hence, some patients selected for endoscopic resection based on this predictive model might still need surgical resection if subsequently found to have unfavorable pathological factors for nodal metastasis. It will be important to compare Fujikawa's prediction model to those EGC classified under the Japanese guidelines' expanded criteria for endoscopic resection to assess the accuracy of this prediction model in identifying those unsuitable for endoscopic resection. The Fujikawa predictive criteria should be carefully validated externally in another cohort of patients with EGC to assess its generalizability.

\section{REFERENCES}

1. Muratami T. Pathomorphological diagnosis. Definition and gross classification of early gastric cancer. Gann Monogr Cancer Res. 1971;11:53-5.

2. Gunji Y, Suzuki T, Hori S, et al. Prognostic significance of the number of metastatic lymph nodes in early gastric cancer. Dig Surg. 2003;20:148-53.

3. Itoh H, Oohata Y, Nakamura K, Nagata T, Mibu R, Nakayama F. Complete 10-year postgastrectomy follow-up of early gastric cancer. Am J Surg. 1989;158:14-6.

4. Bonenkamp JJ, Songun I, Hermans J, Sasako M, Welvaart K, Plukker JT, et al. Randomised comparison of morbidity after D1 and D2 dissection for gastric cancer in 996 Dutch patients. Lancet. 1995;345:745-8.

5. Chiu PW, Teoh AY, To KF, Wong SK, Liu SY, Lam CC, Yung MY, Chan FK, Lau JY, Ng EK. Endoscopic submucosal dissection (ESD) compared with gastrectomy for treatment of early gastric neoplasia: a retrospective cohort study. Surg Endosc. 2012;26(12):3584-91.

6. Gotoda T, Yanagisawa A, Sasako M, Ono H, Nakanishi Y, Shimoda $\mathrm{T}$, et al. Incidence of lymph node metastasis from early gastric cancer: estimation with a large number of cases at two large centers. Gastric Cancer. 2000;3:219-25.

7. Japanese Gastric Cancer Association. Japanese gastric cancer treatment guidelines 2010 (ver. 3). Gastric Cancer. 2011;14(2): $113-23$.

8. Fujikawa H, Sakamaki K, Kawabe T, Hayashi T, Aoyama T et al. A new statistical model identified two-thirds of clinical T1 gastric cancers to be possible candidates for endoscopic treatment. Ann Surg Oncol. 2015. doi:10.1245/s10434-015-4474-7

9. Choi J, Kim SG, Im JP, et al. Endoscopic prediction of tumor invasion depth in early gastric cancer. Gastrointest Endosc. 2011; 73:917.

10. Choi J, Kim SG, Im JP, et al. Comparison of endoscopic ultrasonography and conventional endoscopy for prediction of depth of tumor invasion in early gastric cancer. Endoscopy. 2010; 42:705.

11. Kim JH, Song KS, Youn YH, et al. Clinicopathologic factors influence accurate endosonographic assessment for early gastric cancer. Gastrointest Endosc. 2007;66:901.

12. Puricelli W, et al. Endoscopic mucosal resection: an improved diagnostic procedure for early gastroesophageal epithelial neoplasms. Am J Surg Pathol. 2006;30:114-8.

13. Gotoda T, Yamamoto H, Soetikno RM. Endoscopic submucosal dissection of early gastric cancer. J Gastroenterol. 2006;41:929. 